\section{IMPACT OF ATTITUDES AND BEHAVIORS ON TOOTH LOSS}

https://doi.org/10.25241/stomaeduj.2014.1(2).art.7

Cite this article Giusti L, Salmon ES, White R.

Impact of Attitudes and Behaviors on Tooth Loss. Stoma Edu J. 2014;1(2): 123-130.

\section{Abstract}

Background: Seniors recognize the need for dental care in maintaining quality of life. Research has identified behaviors that are associated with improved dental health. Objective: The objective of this study is to determine the association of certain attitudes and behaviors upon tooth loss.

Method: This study obtained data by random selection from patients in the UOP School of Dentistry via paper survey.

Results: A statistically significant association was evident between tooth loss and seeing a dentist only when absolutely necessary, as well as going five years or more without seeing a dentist. Another significant correlation was made between smoking cigarettes and the use of cocaine or methamphetamines and tooth loss. Factors found to have positive correlations with having 10 or more teeth were found when a dentist was seen twice a year or more frequently, having full time employment for most of the patient's life, tooth grinding at night, the daily use of one or more glasses of alcohol, and brushing and flossing twice a day.

Conclusion: Patients with fewer than ten teeth express attitudes which emphasize the value of their teeth similarly to those patients who have more than ten teeth. Behavior differences between the two groups are various and significant. Long-term retention of teeth can be positively influenced by the avoidance of cigarette smoking, and cocaine and methamphetamine use. Twice -yearly or more regular dental visits, the maintenance of full-time employment, and twice daily brushing and flossing were associated with tooth retention.

Keywords: dentistry, public health, tooth loss, geriatric dentistry

\section{Introduction}

The 2000 Surgeon General's Report on Oral Health (1) found that "oral health is integral to overall health" and that a "silent epidemic of oral disease" exists in the United States. About 30 percent of adults 65 years and older are edentulous.

This research study will look at tooth loss and its association with individuals' attitudes and behaviors.

\section{Attitudes}

Seniors recognize the need for good dental care.

Macek (2) found in his evaluation of NHIS data that the "vast majority of dentate adults age 55 years old or older ... recognize the importance of regular checkups and preventive service". In Anderson's survey of the elderly, he was told that dental care had been expensive but had been given priority (3). In Mckenzie's interviews of senior citizens, he was told "teeth are important" (4).

Homeless drug abusers in Stockholm placed a high value on their oral health and wanted to take steps to maintain it when they were interviewed during a rehabilitative phase of life and not during a period of drug abuse (5).

Dental fear may be reflected in an individual's attitude. Pohjola (6) found that people with higher levels of dental fear have poorer dental condition and that the extent of this fear varies by year of birth.

\section{Lola Giusti ${ }^{1 a^{*}}$ Eric S. Salmon ${ }^{16}$ Richard White ${ }^{2 c}$}

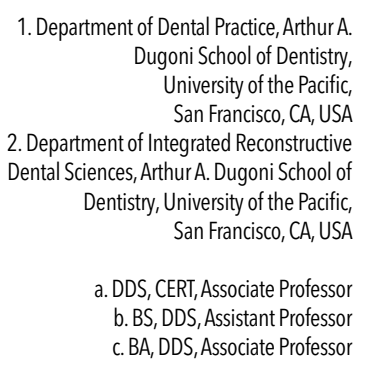

a. DDS, CERT, Associate Professor b. BS, DDS, Assistant Professor c. BA, DDS, Associate Professor

Received: 28 August 2014 Accepted: 08 October 2014

* Corresponding author:

Associate Professor Lola Giusti, DDS, CERT, Department of Dental Practice, Arthur A. Dugoni School of Dentistry, University of the Pacific, 155 Fifth Street, San Francisco, CA 94103, USA Tel: 415.351.7104; Fax: 415.749.4338; e-mail: Igiusti@pacific.edu 


\section{Behaviors}

Research has identified behaviors, which are associated with better oral health.

Thompson found that "routine dental attendance" (dental visits) "is associated with better oral health". Researchers have identified the effect of health beliefs on periodontal maintenance behavior (7). There are multiple studies showing that patient compliance with routine periodontal maintenance treatments prevent the loss of teeth from periodontal disease $(8,9,10,11,12)$. Fisher (13) found that both non-smokers and smokers could be maintained if they were "highly motivated." Health care "habits" or frequency of brushing have a positive correlation with tooth retention $(14,15)$. Bernabe (16) describes a Sense of Coherence (SOC) in health related behaviors: dental attendance, tooth-brushing frequency, reduced sugar frequency, and reduced daily smoking. These behaviors are linked with greater tooth retention.

Mottus (17) concludes that people in disadvantaged circumstances may need to make a stronger personal effort to maintain oral health compared to those in more affluent conditions. Richards (18) unexpectedly found that oral ill health was only slightly elevated in deprived individuals in South Wales.

Several researchers identified the value of "regular attendance" for dental care $(14,19)$. Having regular employment has been associated with better oral health $(20,14)$. Willershausen (21) found as a side result that patients with private insurance showed lower levels of carious lesions. Good nutrition has been linked to significant differences in retention of posterior teeth (22) or to better dental health in general (23).

Some behaviors are associated with poorer dental health.

Arora (24) describes a negative impact on tooth loss from smoking lasting up to 30 years after quitting. Ragnarsson (25) described tobacco as the major independent risk factor for tooth loss in Iceland. Other researchers describe negative impacts from smoking $(8,10$, 26). Methamphetamine use is associated with increased dental disease. Although, individuals who inhale have a lower incidence of dental disease compared to those who inject (27). De Palma (5) found that dental care is less frequently sought during times of drug abuse. Heavy use of alcohol is associated with an elevated level of dental disease $(28,29)$. Reece $(26)$ found that drug addiction has a deleterious effect on dental health and linked tobacco, methadone, and alcohol to these changes.

Removable Prosthodontics have been associated with increased likelihood of subsequent tooth loss (30). Increased age has been associated with tooth loss in a number of studies $(8,9)$. However, other studies concluded age was not a factor (15).

This study reaffirms some of results described above. It also goes further by emphasizing the value placed on teeth by edentulous and partially edentulous individuals. This study also identifies differences in attitudes and behaviors between individuals who were born in or outside California and also those born in or outside the US.

\section{Methods}

Survey participants were randomly selected patients of the University of the Pacific School of Dentistry. The research project and survey instrument were submitted to the University's Institutional Review Board and were given authorization to proceed (Survey). The participants were asked to complete the survey at chairside on a clipboard with pencil or pen. In order to obtain more respondents in the "10 or fewer teeth" category patients were also randomly solicited from the Removable Prosthodontic section of the clinic. These patients sit in a defined area of the clinic and are easily identified.

106 paper surveys were returned. In order to correct for age-related factors fifteen of those surveys were eliminated from the study as those patients were under age 45 , the youngest age of the "10 or fewer teeth" respondents. Thus all of the survey participants were over 45 years of age. Completion of the survey took between five and ten minutes on average, and was done during clinic operation.

There was no patient identifying information entered on the survey. Participants were queried as to their place of birth and year of birth, dental visit history, employment, diet and exercise, habits, alcohol use, parent and child tooth loss patterns, dental home care, attitudes toward their teeth, and the factors that the patient believed were responsible for tooth loss. The survey used a combination of write-in and multiple choice responses. In several instances the survey was conducted orally for those patients who could not read the questions (did not have reading glasses, and/or were disabled).

\section{Results}

For analysis, survey data were divided in to two groups: Patients with more than 10 teeth $(>10)$ and patients with 10 or fewer teeth $(<=10)$. Then, an independent T-test or a chi-square test was utilized to determine whether each survey variable was statistically different between groups. The independent T-test was used for scale variables, 
Patient has more than 10 teeth

Patient has 10 or fewer teeth

1. Place of birth (city, state)

2. How often do you see a dentist?

a. Twice a year or more

b. Once a year

c. Only when I have a problem like pain

d. Only when absolutely necessary, almost never

3. Have you ever gone for five years or more without seeing a dentist?

a. Yes

b. No

4. Describe your diet: (check as many as apply)

a. Lots of basic food groups: meat, vegetables, grains, and fruit

b. Lots of convenience foods like frozen dinners or packaged meals

c. I have a sweet tooth and snack on sweets at least once a day

d. I drink regular (non-diet) sodas at least once a day

e. I chew regular gum (not sugar free)
f. I suck on hard candy, cough drops, or breath mints at least once a day

5. Describe your exercise pattern:

a. I exercise for at least twenty minutes three times a week or more

b. I walk or take the stairs when I get a chance

c. I have a desk job or similar employment and don't exercise much

d. I am very limited in what I can do for exercise so don't move much

6. Describe your employment:

a. I am employed full time and have been for most of my life

b. I work part time and have done so for most of my life

c. I am retired after working full time for most of my life

d. I am retired after working part time for most of my life

e. I worked off and on for most of my life

$f$. I have been a full time homemaker for most of my life

7. Describe any habits that you may have: (circle as many as apply)

a. Smoke cigarettes

b. Smoke pipe or cigar

c. Use smokeless tobacco

d. Have used methamphetamines or cocaine

e. Grind my teeth at night

f. Clench my teeth during the day

8. Describe your alcohol use:
a. Use daily, one or more glasses
b. Use weekly
c. Use at parties, socially
d. Rarely use, if ever
e. Do not consume alcohol at all.

9. Describe your parents: (check as many as apply)

a. They have/ had most or all of their teeth

b. They have lost many of their teeth

c. They wear/ wore partial dentures

d. They wear/ wore complete dentures

10. Describe your children: (check as many as apply)

a. They have most or all of their teeth

b. They have lost many of their teeth

c. They wear partial dentures

d. They wear complete dentures

11. Describe your home care habits: (check as many as apply)

a. I brush and floss twice a day

b. I brush and floss once a day

c. I brush twice a day

d. I brush once a day

e. I do not brush my teeth regularly

f. I use aids like rubber tip stimulators, toothpicks, perio aids, proxabrushes, or stimudents

12. My teeth are
a. Essential
b. Very important
c. Somewhat important
d. Not very important
e. Not at all important

13. What were your average earnings during the 1970's? per year

14. Why do you think that most people lose their teeth?
a. Soft teeth
b. No dentist available
c. Not important to some people
d. Poor brushing
e. Lack of money

15. What year were you born? 
Table 1. Survey answer count and results of analysis

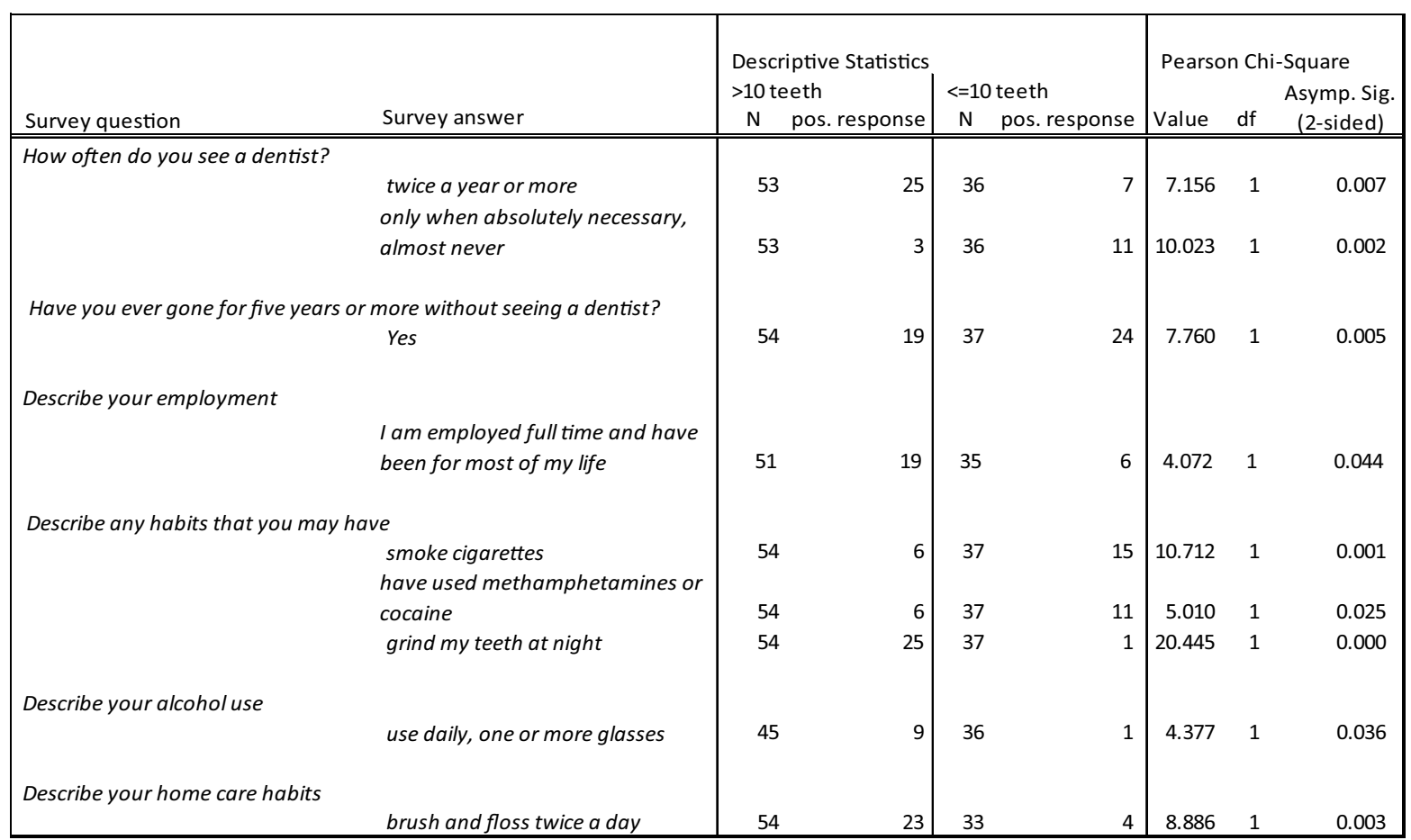

Table 2. Descriptive statistics and analysis

\begin{tabular}{|c|c|c|c|c|c|c|c|c|}
\hline \multirow[b]{2}{*}{ Survey question } & \multirow[b]{2}{*}{ Survey answer } & \multicolumn{4}{|c|}{ Descriptive Statistics } & \multicolumn{3}{|c|}{ Pearson Chi-Square } \\
\hline & & $\begin{array}{l}\text { USA } \\
\mathrm{N}\end{array}$ & $\begin{array}{l}\text { orn } \\
\text { pos. } \\
\text { response }\end{array}$ & $\begin{array}{l}\text { Nor } \\
\mathrm{N}\end{array}$ & $\begin{array}{l}\text { A born } \\
\text { pos. } \\
\text { response }\end{array}$ & Value & $\mathrm{df}$ & $\begin{array}{l}\text { Asymp. } \\
\text { Sig. (2- } \\
\text { sided) }\end{array}$ \\
\hline \multicolumn{9}{|c|}{$\begin{array}{l}\text { My teeth are __ to } \\
\text { me. }\end{array}$} \\
\hline & $\begin{array}{l}\text { - essential } \\
\text { - somewhat } \\
\text { important }\end{array}$ & $\begin{array}{l}82 \\
80\end{array}$ & 55 & $\begin{array}{l}23 \\
20\end{array}$ & $\begin{array}{l}10 \\
3\end{array}$ & $\begin{array}{l}4.240 \\
4.454\end{array}$ & 1 & $\begin{array}{l}.039 \\
.035\end{array}$ \\
\hline
\end{tabular}

"Age" and "Income in the 1970's." All other variables were nominal, so the chi-square test provided analysis of group differences. To avoid the possibility of age differences between groups confounding the results, survey results from patients under 45 years old were eliminated from the analysis. Subsequently performed chi-squared analysis showed age to be statistically similar between groups.

More patients in the $<=10$ group currently smoke and have a history of cocaine or methamphetamine use. This group was also significantly more likely to have gone 5 or more years without going to a dentist and to say that they only went to the dentist "when absolutely necessary, almost never" (Table 1).

Patients in the $>10$ group indicated more often that they had been employed full time for most of their lives. Brushing and Flossing twice per day was more common within this group, as well as self-reported bruxism. They were more likely to indicate that they go to the dentist "twice a year or more" and consume alcohol daily.
In addition to comparing groups based upon their level of edentulism, the survey responses from patients born in the United States were compared to those from patients born outside the United States. Statistical analysis was done on each of the survey variables as described previously. Both groups were equally likely to choose "very important" to describe how they feel about their teeth. Patients born within the United States more often stated that their teeth are "essential" to them. Collectively, patients born in other countries were more likely to choose the "somewhat important" option (Table 2).

The next analysis focused on the differences between people born in California and outside California. The data show that patients born outside of California were significantly more likely to say they "rarely, if ever" use alcohol. In addition, this group was more likely to indicate they go to the dentist once per year than the California. 


\section{Discussion}

It is important to note that our findings address those individuals who have made an effort to obtain dental services at the University of the Pacific Dental School Main Clinic and do not address the experiences of persons who are not currently seeking dental care. Our hypothesis is that patients who are partially or completely edentulous would differ qualitatively in attitudes and/ or behaviors from patients with most of their teeth. That these two groups would differ attitudinally regarding the value of their teeth was not supported. Both groups categorized their teeth as "essential to me."

Participants born outside the United States were slightly more likely to call their teeth "somewhat important to me," but this response was not associated with tooth loss in that group. This finding challenges the widely held belief of many dentists that partially and completely edentulous patients do not value their teeth as much as dentate patients do.

Behavioral differences between the cohorts were multiple and significant. Partially or completely edentulous patients in the study were more likely to have gone for five or more years without seeing a dentist. This same group was also more likely to qualify their frequency of seeking dental care as being "only when absolutely necessary, almost never." In their recent article regarding the impact of dental visit patterns on clinical oral health, Crocombe et al, at the University of Adelaide, found a significant association between opportunistic dental visit behavior and decayed, missing, and filled surfaces as well as missing teeth because of caries (19).

Therefore, this correlation has been supported by other researchers. As evidenced by their presence at the dental school, these individuals may be making a concerted effort to obtain necessary dental services and could thereby be changing their previous dental visiting pattern. In other words, the history of little or no dental care could be part of a patient's history of neglect but not the current status of treatment.

Partially or completely edentulous patients were also more likely to smoke cigarettes. Patients who smoke constituted $40.54 \%$ of this cohort compared to non-smokers who represented only $11.11 \%$ of these individuals. Another correlation found between partial and complete tooth loss is the use of methamphetamines or cocaine.

Among partially or completely edentulous patients $29.73 \%$ used these drugs, while only $11.11 \%$ of the dentate group self-reported such usage. Recreational drug use has been found to be correlated to increased dental disease by Shetty et al in a 2010 article in JADA (27). This study supports these associations. The authors acknowledge that the use of these substances may have been underreported in this study due to embarrassment.

More positive responses from the dentate group were found on query regarding regular dental visits and steady employment. Financial resources and access to care through dental insurance seem logically to be more likely to lead to regular dental visits and thereby to the retention of teeth. Likewise, twice daily brushing and flossing were found to be associated with tooth retention in this group.

Tooth grinding was found to be more likely in the dentate group than in the 10 or fewer teeth cohort. One cannot grind teeth that are missing, so this finding is not surprising. Somewhat more counterintuitive is the finding of daily use of alcohol in the dentate group.

The findings regarding diet and exercise were also of interest. There were no statistically significant differences between the two groups in these parameters. Both groups self-reported similar dietary habits and exercise patterns. This finding refutes the hypothesis that partial or fully edentulous patients would engage in "nonhealthy" dietary and exercise patterns. The use of regular (non-diet) sodas, regular gum, and candy, cough drops or breath mints reflected no statistically significant differences between these patients.

Similarly, there were no differences in exercise patterns between the cohorts. The researchers have contemplated these findings and postulate that within these populations there were prior periods of neglect in a given patient's life (periods of five years or more without seeing a dentist) and if as demonstrated by their presence in the dental school clinic these patients are reflecting an improved attitude toward their overall health and pattern of seeking health care.

A correlation between the dental status of survey respondents and that of their parents was not confirmed.

Participants were queried as to the dental status of their children, and there were an insufficient number of responses in this category to establish such a comparison.

It was postulated by the authors that dentate patients would be more likely to use dental hygiene aids like rubber tip stimulators, toothpicks, perio aids, proxabrushes or stimudents, but no such differences were found between groups.

The researchers attempted to verify an interdependence between earnings in the 
1970s and dentate status but no association was evidenced in this study.

Many patients reported difficulty remembering their income at that time, which diminished the response rate.

There was a strong negative correlation between patients who are currently employed full time and the behavior of only seeking dental care when absolutely necessary.

Of those patients who are full time employees $(n=24) 15$ see a dentist once or twice a year, and 9 see a dentist only when there is a problem like pain. These data have implications for patients who may have dental benefits and/ or access to care but do not use dental services.

In exploring the patients' beliefs regarding the reasons that "most people lose their teeth", both groups were likely to cite "soft teeth," "no dentist available," "not important to some people," "poor brushing" and "lack of money." There were no statistically significant differences between groups in this regard.

Those individuals defining their teeth as "essential" evidenced positive associations with twice yearly dental visits, and also with once yearly dental visits. There was a negative correlation found between these patients and only seeing a dentist when there is a problem, and with only seeing a dentist when absolutely necessary.

This study did not query patients regarding their gender, education, ethnicity or current income. It was done as a pilot project to determine feasibility for future research. This area of dental research holds promise: recently an exploration of oral health disparities among white, black, and Mexican-American elders demonstrated persistent differences between these patients (31). Further study may assist dental practitioners in developing meaningful, effective treatment strategies to address the needs of an aging population.

In conclusion, this study demonstrates some similarities as well as key differences between partially or fully edentulous patients and patients with a greater number of teeth. Attitudes regarding the value of their teeth did not differ between these groups, but behaviors such as regular dental visits, twice daily brushing and flossing, the avoidance of smoking and recreational drug use, and maintaining steady employment were found to vary between the cohorts. It is the authors' belief that increased lifespan can be better enjoyed with good dental health, and this study reinforces what many researchers have established in prior studies regarding the retention of teeth.

Access to care continues to be an issue for many patients, and education is necessary to help patients prioritize their dental health. Practitioners should develop the awareness that they have important opportunities in the course of treatment to discuss habits such as smoking, recreational drug use as well as evidence based on patterns of dental care utilization, or lack of, with their patients, and that such influence can be extremely beneficial.

The knowledge that patients needing complete or partial dentures value their teeth as much as dentate patients may cause a dentist to view these individuals differently. The factors discussed above deserve greater attention in future research about disparities in dental health.

\section{Bibliography}

1. Satcher DS. Surgeon General's report on oral health. Public Health Rep 2000;115(5):489-490.

2. Macek MD, Cohen LA, Reid BC, Manski RJ. Dental visits among older U.S. adults, 1999: the roles of dentition status and cost. J Am Dent Assoc 2004;135(8):1154-1162; quiz 1165.

3.Andersson K, Nordenram G. Attitudes to and perceptions of oral health and oral care among community-dwelling elderly residents of Stockholm, Sweden: an interview study. Int J Dent Hyg. 2004;2(1):8-18.

4. McKenzie-Green B, Giddings LS, Buttle L, Tahana K. Older peoples' perceptions of oral health: 'it's just not that simple'. Int J Dent Hyg 2009;7(1):31-38.

5. De Palma P, Nordenram G. The perceptions of homeless people in Stockholm concerning oral health and consequences of dental treatment: a qualitative study. Spec Care Dentist 2005;25(6):289-295.
6. Pohjola V, Lahti S, Vehkalahti MM, Tolvanen M, Hausen H. Age-specific associations between dental fear and dental condition among adults in Finland. Acta Odontol Scand 2008;66(5):278-285.

7. Kühner MK, Raetzke PB. The effect of health beliefs on the compliance of periodontal patients with oral hygiene instructions. J Periodontol 1989;60(1):51-56.

8. Al-Shammari KF, Al-Khabbaz AK, Al-Ansari JM, Neiva R, Wang HL. Risk indicators for tooth loss due to periodontal disease. J Periodontol 2005;76(11):1910-1918.

9. Chace R Sr, Low SB. Survival characteristics of periodontally-involved teeth: a 40-year study. J Periodontol 1993;64(8):701-705.

10. Chambrone LA, Chambrone L. Tooth loss in wellmaintained patients with chronic periodontitis during long-term supportive therapy in Brazil. J Clin Periodontol 2006;33(10):759-764. 
11. König J, Plagmann HC, Langenfeld N, Kocher T. Retrospective comparison of clinical variables between compliant and non-compliant patients. J Clin Periodontol 2001;28(3):227-232.

12. Miyamoto T, Kumagai T, Lang MS, Nunn ME. Compliance as a prognostic indicator. II. Impact of patient's compliance to the individual tooth survival. J Periodontol 2010;81(9):1280-1288.

13. Fisher S, Kells L, Picard JP, Gelskey SC, Singer DL, Lix L, et al. Progression of periodontal disease in a maintenance population of smokers and non-smokers: a 3-year longitudinal study. J Periodontol 2008;79(3):461-468.

14. Guiney H, Woods N, Whelton H, Mullane DO. Nonbiological factors associated with tooth retention in Irish adults. Community Dent Health 2011;28(1):53-59.

15. Nederfors T. Attitudes to the importance of retaining natural teeth in an adult Swedish population. Gerodontology 1998;15(2):61-66.

16. Bernabé $E$, Watt $R G$, Sheiham A, Suominen $A L$, Vehkalahti MM, Nordblad A, et al. Childhood socioeconomic position, adult sense of coherence and tooth retention. Bernabé $E$, Watt RG, Sheiham $A$, Suominen AL, Vehkalahti MM, Nordblad A, Uutela A, Kivimäki M, Tsakos G. Community Dent Oral Epidemiol 2012;40(1):46-52.

17. Mõttus R, Starr JM, Deary IJ. Predicting Tooth Loss in Older Age: Interplay Between Personality and Socioeconomic Status. Health Psychol (in press).

18. Richards W. Oral ill-health and deprivation among patients of a general dental practice in South Wales. Prim Dent Care 2002;9(3):105-112.

19. Crocombe LA, Broadbent JM, Thomson WM, Brennan DS, Poulton R. Impact of dental visiting trajectory patterns on clinical oral health and oral health-related quality of life. J Public Health Dent 2012;72(1):36-44. 20. d'Orsi E, Xavier AJ, Ramos LR. Work, social support and leisure protect the elderly from functional loss: EPIDOSO study. Rev Saude Publica 2011;45(4):685-692.
21. Willershausen B, Witzel $S$, Schuster $S$, Kasaj A. Influence of gender and social factors on oral health, treatment degree and choice of dental restorative materials in patients from a dental school. Int J Dent Hyg 2010;8(2):116-120.

22. de Andrade FB, de França Caldas A Jr, Kitoko PM. Relationship between oral health, nutrient intake and nutritional status in a sample of Brazilian elderly people. Gerodontology 2009;26(1):40-45.

23. Musacchio $E$, Perissinotto E, Binotto $P$, Sartori L, SilvaNetto F, Zambon S, et al. Tooth loss in the elderly and its association with nutritional status, socio-economic and lifestyle factors. Acta Odontol Scand 2007;65(2):78-86.

24. Arora M, Schwarz E, Sivaneswaran S, Banks E. Cigarette smoking and tooth loss in a cohort of older Australians: the 45 and up study. J Am Dent Assoc 2010;141(10):1242-1249.

25. Ragnarsson E, Elíasson ST, Olafsson SH. Tobacco smoking, a factor in tooth loss in Reykjavík, Iceland. Scand J Dent Res 1992;100(6):322-326.

26. Reece AS. Dentition of addiction in Queensland: poor dental status and major contributing drugs. Aust Dent J 2007;52(2):144-149.

27. Shetty V, Mooney LJ, Zigler CM, Belin TR, Murphy D, Rawson $R$. The relationship between methamphetamine use and increased dental disease. JADA 2010;141(3):307-318.

28. Klein BE, Klein R, Knudtson MD. Life-style correlates of tooth loss in an adult Midwestern population. J Public Health Dent 2004;64(3):145-150.

29. Kranzler HR, Babor TF, Goldstein L, Gold J. Dental pathology and alcohol-related indicators in an outpatient clinic sample. Community Dent Oral Epidemiol 1990;18(4):204-207.

30. Chen X, Clark JJ, Naorungroj S. Length of tooth survival in older adults with complex medical, functional and dental backgrounds. J Am Dent Assoc 2012;143(6):566-578.

31. Wu B, Liang J, Plassman BL, Remie RC, Bai L. Oral health among white, black, and Mexican-American elders: an examination of edentulism and dental caries. J Public Health Dent 2011;71(4):308-317. 